\section{Cooperação Brasil-Argentina em Cristalografia Estrutural}

YVONNE P. MASCARENHAS

E M DEZEMBRo de 1971 recebi um inesperado convite para participar de um congresso do Grupo Iberoamericano de Cristalografia, a ser realizado em janeiro de 1972 em Valdívia, Chile. Minha resposta foi um imediato e entusiástico sim, com a sensação de ter recebido um maravilhoso presente de Papai Noel. Estando no Brasil há 10 anos, após uma estadia de 15 meses no Departamento de Cristalografia da Universidade de Pittsburgh (EUA), esta seria uma excelente oportunidade para conhecer a comunidade cristalográfica latino-americana que, embora antecipasse ser pequena, deveria constituir uma boa fonte para interações e colaborações futuras. Além disso, tal comunidade sempre tivera muito interesse e admiração por aquele país por sua tradição de comportamento democrático, ímpar na América Latina, através de sucessivas eleições e que, há cerca de quase um ano, elegera Allende, o primeiro governo socialista a chegar ao poder por via democrática pelo voto popular.

Na minha participação no evento causou-me excelente impressão relativamente à qualidade dos cristalógrafos que ali encontrei, podendo-se citar, entre outros, da Argentina, Aldo F. Craievich do Departamento de Física da Universidade Nacional de Córdoba e Eduardo E. Castellano e seus orientados, que logo se tornariam colaboradores; Oscar E. Piro e Blás Rivero do Departamento de Física da Universidade Nacional de La Plata. Do Chile, Mario Suwalski, Oscar Vitke, Hilda Cid e Carmen Escobar.

Durante o Congresso procurei convencer vários participantes latino-americanos a virem a São Carlos como pesquisadores convidados. Após uma breve visita a São Carlos, Aldo Craievich aceitou o convite para juntar-se ao nosso Laboratório de Cristalografia, onde deu início a atividades na área de estudo de materiais vítreos por espalhamento de raios $\mathrm{X}$ a baixo ângulo (SAXS), adquirindo, com financiamento da Fapesp, os equipamentos necessários.

Ainda em agosto de 1972 participei do Congresso da União Internacional de Cristalografia realizado em Kyoto, Japão, seguido de estágio no Departamento de Química da Universidade de Princeton e no Departamento de Cristalografia da Universidade de Pittsburgh (EUA). Pude, então, constatar os enormes progressos metodológicos na pesquisa cristalográfica trazidos pela evolução da automação da coleta de dados de difração de raios X por monocristais e nos métodos computacionais já disponíveis. Por essa razão fiquei absolutamente convencida da impossibilidade de realizar pesquisa em cristalografia estrutural, competitiva em nível internacional, sem contar com os modernos equipamentos disponíveis na maioria dos bons laboratórios.

Ao retornar ao Brasil encaminhei pedido de auxílio à Fapesp com a finalidade de adquirir um moderno difratômetro automático para monocristais - o Cad4 da Enraf-Nonius, dotado de um computador PDPll da Digital - que permitiria a realização da maior parte dos cálculos necessários para a determinação de estruturas moleculares e cristalinas por difração de raios X. Tendo este equipamento chegado ao Brasil em 1975 e considerando-se que o mesmo poderia ser utilizado em nível latino-americano, foi realizado em 1976 um Curso Latino-americano sobre Métodos Diretos para Resolução de Estruturas por Difração de Raios X, com apoio financeiro de várias entidades internacionais e nacionais, o que permitiu a vinda dos maiores especialistas da área, entre os quais destacamos M. Woolfson e Peter Main, da Universidade de York (Inglaterra); Isabella e Jerome Karle, do Naval Research Laboratory (Washington DC, EUA); Herbert 
Hauptmann, da Medical Foundation of Buffalo (EUA), que receberia junto com J. Karle, o prêmio Nobel de Química em 1988; Paul Ewald, o criador do conceito de espaço recíproco em Cristalografia, os quais atuaram como professores convidados, além de contar-se com a participação de cerca de 20 cristalógrafos latino-americanos, a maioria dos quais já meus conhecidos de Valdívia.

Durante o curso foi discutida a conveniência de contar-se com a participação de, pelo menos, mais um pesquisador que seria convidado a vir ao Brasil como professor visitante, com uma bolsa do CNPq. Afortunadamente, Eduardo Ernesto Castellano aceitou o convite, dando inicio assim a uma intensa colaboração entre o Laboratório de Cristalografia do Instituto de Física de São Carlos e o Departamento de Física da Universidade Nacional de La Plata (Argentina).

\section{Atividades São Carlos-La Plata}

A colaboração entre os dois grupos de pesquisa, iniciada nos últimos anos da década de 70 , persiste até os dias atuais. Os participantes de La Plata foram inicialmente Oscar E. Piro e Blás E. Rivero, abordando problemas relacionados à estrutura de nitroprussiatos (materiais com interessantes propriedades eletrônicas e vibracionais) e muitos outros complexos de metais de transição com ligantes orgânicos, com a finalidade de esclarecer suas propriedades espectrais. É importante salientar que tais materiais eram obtidos em grupos de pesquisa em química, que envolviam renomados pesquisadores argentinos, como P.J. Aymonino e E.J. Baran e vários de seus orientandos de pós-graduação.

As atividades desenvolvidas por E.E. Castellano e colaboradores de La Plata não se limitaram apenas aos grupos de pesquisa argentinos mas estenderam-se a vários grupos de pesquisa brasileiros, entre os quais os liderados por Geraldo Vicentini do Ins- tituto de Química da USP, por Alzir Azevedo Baptista do Departamento de Química da UFSCar e por Ademir Neves, do Departamento de Química da Universidade de Santa Catarina, além de outros grupos de pesquisa sediados na Europa, como o de J.S. Casas da Universidade de Santiago de Compostella (Espanha) e de Angela Denil de Namor, pesquisadora argentina radicada na Universidade de Guildford, Surrey (Inglaterra).

De grande importância foram as atividades exercidas por Castellano, relacionadas à formação de recursos humanos para a área da cristalografia mediante a orientação de cerca de 10 alunos de pós-graduação, que hoje exercem atividades de ensino e pesquisa em várias universidades brasileiras.

Nos últimos três anos Javies Ellena, que se doutorou em La Plata, participa do Laboratório de Cristalografia de São Carlos realizando estágio pós-doutoral, com uma com bolsa de pós-doutoramento concedida pela Fapesp. Exerce intensa atividade na área de determinação de estrutura de substâncias inorgânicas com interessantes propriedades magnéticas ou ferroelétricas, de moléculas orgânicas naturais e sintéticas de interesse biológico e de complexos de metais com ligantes orgânicos com potencial aplicação como descontaminantes de metais pesados em ambientes poluídos.

Demonstrando a importância das colaborações realizadas entre membros do Laboratório de Cristalografia do IFSC-USP e participantes sediados na Argentina, nos últimos 25 anos podemos citar a publicação de mais de 80 artigos científicos em revistas internacionais com rigoroso sistema de arbitragem.

\section{Trabalhos por SAXS}

Os trabalhos conduzidos por Aldo Felix Craievich e seus alunos de pós-graduação versaram essencialmente sobre problemas de transição de fase em materiais vítreos e componentes de cimento. Tais trabalhos 
contribuíram para a formação de recursos humanos para atuarem na área, alguns deles atualmente exercendo atividades profissionais no Departamento de Engenharia de Materiais da UFSCar, no Centro Tecnológico da Aeronáutica de São José dos Campos e no Departamento de Física da Unesp de Rio Claro. Posteriormente Aldo F. Craievich e a autora deste artigo interessaram-se pelo estudo de proteínas em solução, tendo orientado diversas teses em que se determinaram as características estruturais de várias toxinas ofídicas, em colaboração com os pesquisadores J. Laure e R. Giglio do Departamento de Bioquímica da Faculdade de Medicina de Ribeirão Preto/ USP e de variações conformacionais da albumina sérica humana em diferentes condições de $\mathrm{pH}$. Os estudantes envolvidos nessas pesquisas atualmente fazem parte do corpo docente do Departamento de Física do IBILCE /Unesp, campus de Rio Preto, para onde convergiram jovens doutores que pretendiam estruturar um grupo de pesquisa em biofísica molecular.

Em 1985 Aldo F. Craievich deixou o IFSC, tendo então se dedicado à importante missão de estruturar o Laboratório Nacional de Luz Síncrotron e a outras atividades de pesquisa em colaboração com estudantes e pesquisadores brasileiros no Instituto de Física da USP, onde ocupa o cargo de professor titular. Deve-se ainda mencionar que os trabalhos desenvolvidos em São Carlos geraram cerca de dez publicações em revistas internacionais.

\section{Universidade Nacional de Córdoba}

Em meados da década de 80 iniciei uma nova fase de pesquisa, tendo meu interesse despertado por estudos estruturais de materiais tecnológicos, em especial cerâmicas ferroelétricas que se apresentam sob a forma de agregados policristalinos. Tendo logrado, com a colaboração de meu orientando em doutoramento, Carlos de Oliveira Paiva Santos, implantar as condições expe- rimentais para as medidas de difração de raios $\mathrm{X}$ por materiais policristalinos e $\mathrm{O}$ software necessário à sua interpretação para a utilização do método de Rietveld, foi possível concluir uma tese que pode ser considerada seminal no país para esta metodologia. No início da década de 90 surgiu a possibilidade de receber uma jovem doutora do Departamento de Química da Universidade Nacional de Córdoba, Silvia Cuffini, para uma estada pós-doutoral no nosso Laboratório, com a finalidade de realizar a caracterização estrutural de uma série de compostos cerâmicos policristalinos que ela havia sintetizado para a sua tese de doutoramento. O projeto casava-se perfeitamente com os nossos novos interesses de pesquisa e imediatamente solicitei uma bolsa de pós-doutoramento à Fapesp e, posteriormente, uma bolsa de pesquisadora visitante ao $\mathrm{CNPq}$, as quais permitiram a sua permanência em São Carlos por cerca de dois anos e meio, tempo em que exerceu intensa atividade de pesquisa em colaboração tanto comigo quanto com outros docentes do IFSC e do Departamento de Física da Universidade Federal de São Carlos. Dessas interações resultaram cinco trabalhos, que foram concluídos e publicados em revistas especializadas.

Em 1998 estagiou por alguns meses em São Carlos o estudante de doutoramento Carlos Meriles, que estava na fase final de seus trabalhos de tese. Ele estudou transições de fase em vários compostos que continham grupos bi-fenilos em suas moléculas, utilizando tanto as técnicas de monocristal quanto de policristal a baixa e alta temperaturas. Foi possível alcançar bons resultados, que deram origem a dois artigos que foram submetidos e aceitos para publicação em revistas internacionais especializadas.

Yvonne P. Mascarenhas atua no Laboratório de Cristalografia, Departamento de Física e Informática, Instituto de Física de São Carlos, USP. yvonne@if.sc.usp.br 